\section{India's Recent Development Dynamics and Challenges}

\section{Dr Diganta Das ${ }^{\dagger}$}

In recent decades, India managed to achieve a sustained economic growth due to sweeping macroeconomic changes and liberalisation since the 1990s. With services sector primarily propelled by the Information Technology (IT) industries took the lead role in economic growth. India has managed to increase its GDP growth substantially. With growing location of IT industries, major Indian cities have become the new engines of growth. While the digerati class demanded world-class infrastructure from the city governments, cities have also become a primary node for migrants from surrounding regions in search of a better job and living opportunities. Increasing urban population, therefore, soon affected the existing infrastructure and made Indian cities highly divided between have and have-nots in relation to access to even essential services such as water, power and transport infrastructure. Cities in India have splintered where we witness islands of affluence with gated condominiums, world-class IT industries and shopping complexes as well as large spaces of hopelessness where ordinary urban folks struggle for everyday amenities such as drinking water (Graham and Marvin, 2001; Das, 2015).

Realising the challenges of urban India, and impending infrastructure issues, governments have been implementing several urban development programmes such as JNNURM (Jawaharlal Nehru National Urban Renewal Mission) during the last decade, and now the current government is banking on Smart Cities Mission and AMRUT (Atal Mission for Rejuvenation and Urban Transformation) programme to provide essential infrastructure and transform India with enhanced quality of living. However, with hard infrastructural development, there is also need to work on social sector and development programmes that create awareness towards incremental social change. Recently, two Bollywood movies Toilet-Ek Prem Katha (2017) and Padman (2018) acted by prominent actors such as Akshay Kumar, Bhumi Pednekar and Radhika Apte in lead roles stormed the headlines for making films with strong social messages that resembles the current government's effort on transforming India through Swachh Bharat Abhiyan (Clean India Movement) for provision of basic hygiene and sanitation infrastructure. Further, the central government in New Delhi have introduced other social programmes such as Beti Bachao Beti Padhao (Save girl child, educate a girl child) programme to create awareness for the welfare of girl child across India. While the society has welcomed these social initiatives, its reach and impact will perhaps take some time to reflect given India's geographical extent and bureaucratic challenges at both federal and subnational level.

The current issue of Space and Culture, India is a potpourri of one review article, three special articles, three research articles, and one perspective article. This issue looks into the context of empowerment, geographies of children, migration, and sanitation issues. The review article by Esita Sur titled Triple Talaq Bill in India: Muslim women as political subjects or victims? The author has argued against the homogenised view of Muslim women as assumed by the Bill. The author argues that the Bill need to recognise the intersectionality between the sociocultural, the religious and the economic facets of the life as lived by Muslim women.

\footnotetext{
${ }^{+}$Assistant Professor, \& HD Research Coordinator, Humanities and Social Studies, Nanyang Technological University, Singapore, Email: diganta.das@nie.edu.sg (C) 2018 Das. This is an Open Access article distributed under the terms of the Creative Commons Attribution License (http://creativecommons.org/licenses/by/2.0), which permits unrestricted use, distribution, and reproduction in any medium, provided the original work is properly cited.
} 
In their article titled Ayodhya: The imageability and perceptions of cultural landscapes, Rana P. B. Singh and Sarvesh Kumar seek to examine how the visitors/pilgrims perceive and imagine Ayodhya vis-a-vis that of the dwellers. Theoretically, this work draws from Kevin Lynch's understanding of imageability (1960). Based on Lynch's work, the authors seek to understand responsive perception through the elements of the path, edge, node, district, and landmark, marked onto cognitive maps. As such, this work extends and adapts Lynch's work to the Indian context. The authors collected data through surveys of the dwellers and the pilgrims, to collate their first impressions of the city and their understanding of the symbolism of the things around them. The survey also examines the extent to which different buildings and architectural monuments possess sacredness and symbolic identity, and uniqueness to the respondents. As such, geographic and mapping tools are central to this article. Different perceptual sketches were generated for the dwellers and the pilgrims, mapping what they perceived as crucial roads and important landmarks. This allows a visual display for comparisons to be made between the two groups, drawing out similarities and differences. Through the maps, the authors argue that Ayodhya is a faithscape that can only be understood on a personal level, through the way one connects to the spiritual realm. This faithscape is made up of physical and cultural elements, on top of human actions and performances. In an era of burgeoning urbanisation, this paper highlights how different aspects of a city that we take for granted (possibly as ubiquitous and mundane) could potentially hold a greater significance to another group or individual. As such, we need to be cognizant of the power relations behind competing for land uses and land use plans.

In the article by Shatabdi Saha, Rupak Goswami and Sujit Kumar Paul, titled Recursive Male Outmigration and the Consequences at Source: A Systematic Review with Special Reference to the Left-behind Women mainly focuses on trends of "feminisation of agriculture" and to analyse the impact of male out-migration on female empowerment. This work is in line with the theoretical school of the "migration leftbehind," which emphasises the life experiences and the well-being of those left behind. The paper concludes that studies of the impacts on productivity of the "feminisation of agriculture" do not come to a consensus. Moreover, the impact of migration on the empowerment of women is shaped by their attributes (age, education, and marital duration), nature and amount of remittance, family structure, local culture and the interplay between these factors. There are both negative and positive changes in the lives of women. Studying the experience of these (neglected) left-behind women in rural areas would shed light on the policies and interventions necessary to facilitate greater female empowerment at the origin.

In the third article entitled titled Child Protection System and Challenges in Pakistan on the special article category by Venkat Pulla, Maliha Gul Tarar, and Amber Ali focusses on issues of child abuse in South Asian context and brings out various factors responsible for child protection in Pakistan. The authors noted that both psychological and physical abuse are primary factors in children quitting schools as well as home/neighbourhood in relation to South Asia. The authors argue that internal factors such as poverty, socio-economic class, etc. pose challenges in relation to child abuse and their protection. External factors such as terrorism and geopolitical issues have led to the attack of schools leading to dangers to children. The paper further delves into the existing child protection programmes of Pakistan and various challenges and concludes by emphasising the need for community involvement in bringing a solution to the issue of child protection.

In the research article category, the first article titled Migration Policy of the Regions of the Republic of Kazakhstan: Socio-political mechanisms of easing the interethnic tension by Gulsara Kappassova aims to study the interethnic relations in the Republic of Kazakhstan. The author sought to develop a methodology to standardise an Index of Ethnic Tension. Through this index, the author 
assessed the current situation in Kazakhstan to come up with suggestions for managing and improving the interethnic relations. Empirically, this paper sought to create a methodological approach to the quantitative analysis of interethnic tension by using the data. Through the findings, the author has concluded that the interethnic tension is at a low level, although there is some tension latent. With the indices generated, the author gave some recommendations for areas of improvement.

The next research article by Kaberi Koner titled Sanitation and Hygiene of Darjeeling City: A Crisis for Women and Adolescent Girls focusses on the lack of public toilets in the touristic city of Darjeeling and explores the present situation of sanitary provision through the lens of everyday experiences of women and adolescent girls. This research was based on a qualitative ethnographic study carried out between 2015 and 2017. Through the use of structured and semi-structured questionnaires, focus group discussions, informal interviews, and oral storytelling, this research sought to collect the authentic, lived realities of the women and the adolescent girls. The paper concludes that the women and teenage girls face disproportionately more struggles in meeting their sanitation needs. These problems have been characterised into - health problems, waste of time and money, issues of security and the matter of dignity. While there has been a considerable effort by the government and civil society organisations to bring about better sanitation in India, the supply is still far short of demands, and there is plenty of room for improvement. Particularly since urbanisation continues to be a strong and rapidly growing trend in India today, demands for sanitation will continue to grow. Koner's work on the experience of poor women and adolescent girls and her recommendations would be particularly relevant in this context.

The research article by Utpal Panja and Biswaranjan Mistri titled Human-Elephant Conflict in Sonamukhi C.D. Block of Bankura District; West Bengal seeks to study the major causes of human-animal conflict by analysing the major causes and consequences of the changing behaviour of elephants and the land use patterns of the affected populations. Primary data was collected through in-depth interviews from the grassroots level through door-to-door surveys, and various secondary data were further analysed. The results were then presented through geographical tools like maps and satellite imagery. The authors were able to succinctly map the push and pull factors leading to the elephants' migration into the study area, and the decreasing habitat of the elephants. The authors argue that the conflict is a result of the expansion of human land use, which is not only reducing the forested area but also affecting the forest ecosystem.

The final article by Hemant Patidar titled Women's Empowerment and Fertility Behaviour among the Tribals of Rajasthan, India investigates the role of women's empowerment on fertility behaviour. Primarily focusing on the Empowered Action Group State of Rajasthan, this research sought to examine the relationship between female empowerment and fertility, in relation to tribal women. The paper argues that women's empowerment is negatively associated with fertility behaviour. Women with higher education levels have fewer children than those who are less educated or illiterate. Self-employed women and women involved in government and private jobs are more likely to have fewer children than those in unpaid family work or are family cultivators. Exposure to the media is also a significant determinant of fertility behaviour amongst women. Further, the author argues that women who do not have a role in household decision-making and communication on reproductive issues are likely to have more children.

\section{References}

Das, D. (2015). Making of high-tech Hyderabad: Mapping neoliberal networks and ground realities, Singapore Journal of Tropical Geography, 36(2), 231-248, doi:doi:10.1111/sjtg.12112

Graham, S. (2001). The city as sociotechnical process: Networked mobilities and urban social inequalities, City, 5(3), 339-349. 
Lynch, Kevin (1960). The image of the city, MIT

Press, Cambridge, MA. 